Journal of Contemporary Educational Research

Research Article

\title{
An Empirical Study on the Online + Offline Flipped Classroom Teaching Model for Photoshop in the Age of Internet
}

\author{
Qun $\mathrm{Xu}^{1,2}$, Jaewook Shin ${ }^{2 *}$, Kim Ae-Hyun ${ }^{2}$ \\ ${ }^{1}$ Shanghai Lida University, China \\ ${ }^{2}$ Dong-A University, South Korea
}

\begin{abstract}
This paper mainly investigates the research status of online + offline flipped classroom teaching mode for Photoshop, studies the theoretical basis of flipped classroom, and summarizes the research direction of online + offline flipped classroom. In addition, the Photoshop flipped classroom teaching was carried out. The empirical research mainly studies the application of the flipped classroom from the aspects of preliminary preparation and teaching design. Lastly, the effect of the flipped classroom is studied in order to provide data and basis for follow-up research.
\end{abstract}

Key words: Online offline; Flipped classroom; Photoshop; Teaching mode

Publication date: October, 2020

Publication online: 31 October, 2020

*Corresponding author: Jaewook Shin, xuqun2004@163.com

\section{Photoshop Teaching Mode}

Photoshop is a graphic image processing software produced by Adobe. This software is a basic tool for artistic design creation and plays an important role in the design industry. This course is a professional basic course of art design, an important fundamental course, and the foundation for students to learn subsequent courses (Illustrator, animation production, web page production, graphic creativity, etc.). Currently, the teaching mode of Photoshop is mainly divided into three types: offline teaching (traditional), online + offline flipped classroom (flipped class), and exclusive online teaching (online) (including recording and live broadcasting). For online + offline classrooms, the proper term is "flipped class" and the Chinese translation is "fan zhuan ke tang". The concept of the flipped classroom was proposed by Bergmann and Sams (2012). They recorded class lectures and provided the videos online to enable students to watch and review the teaching contents more conveniently.

\section{The Theoretical Basis of Flipped Classroom}

Ms. Jinling Luo has studied the theoretical basis of flipped classroom, including constructivist learning theory, zone of proximal development theory, and mastery learning theory, etc.

Constructivism theory was put forward by Swiss psychologist Jean Piaget. The main idea is to have a full and comprehensive understanding of students before class, establish student-centered thinking in the learning process, emphasize teamwork, and teachers mainly play the guiding role. The zone of proximal development theory was proposed by child psychologist and teaching psychologist Lev Vygotsky in the 1930s. This theory believes that students have two levels of development, one is the current level of development, and the other is the higher level of problem-solving learned under guidance. The area of gap between the two is termed the zone of proximal development and teaching creates a dynamic zone of proximal development. The third theory was put forward by American psychologist Bloom. He believed that no matter how different students are, as long as they are given enough time 
and correct guidance, every student can complete the assigned content. The learning content is divided into a number of small goals to guide students one by one, from easy to difficult in a step-by-step manner to allow students to learn and master knowledge in a relatively relaxed atmosphere.

After literature review, it was found that many scholars in the field mentioned mastery learning theory. It is generally believed that the flipped classroom is based on this theory, with segmented flipping and stepby-step guidance, so that students can learn and master knowledge in a relatively relaxed environment.

\section{The Research Direction of Flipped Classroom:}

\subsection{Curriculum Research}

In the research of teaching mode, curriculum research is an important part. In curriculum research, researchers will perform analysis on learners, learning content, teaching environment, software, teaching objectives and practical teaching. The practical teaching also includes preliminary preparations for research, teaching examples, and effect analysis etc. All of these are being developed for the macro-curriculum.

\subsection{Empirical Research on Course Teaching}

\subsubsection{Preliminary Preparation}

There are differences in the arrangement of Photoshop courses in different schools. The class hours range from 32 to 64 hours. Differences are mainly based on professional teaching plans, differences in learners and differences in learning conditions. In graphic majors such as advertising design majors, visual majors and other majors, Photoshop is very important as a graphics image processing software, and therefore its proportion of class hours will be higher. For other majors such as fashion design, product design, and interior design, Photoshop accounts for a relatively low proportion of class hours.

For different majors, the offline preliminary preparation is roughly the same. Most schools have professional computer rooms with Photoshop software installed. Excellent computer rooms will have the highest and latest version prepared for students to learn and use. The preliminary preparation for online courses is more complicated and includes:

(1) Online video or live broadcast technical preparation and support. The development of the internet provides a strong background for online development. Teachers prepare and record lessons, and a professional team is needed to deal with postediting to ensure the quality of the videos. Images and contents are two important aspects that attract students. Currently, only the school's free server is required to upload videos to the internet, or it can be done on some free platforms. If you choose to do online live broadcast, you need more powerful technical support. The quality of the footage and sound, the realtime nature of the broadcast, and the teacher-student interactions etc. are all technical problems that need to be solved.

(2)Lecturer course preparation support. To integrate advantages of offline teaching into online; the content and form of the courses, the frequency of interaction; the overall arrangement of online and offline courses, how online and offline teaching complement each other; and how to mobilize the initiative of students to ensure the effects of learning, etc. These are questions that lecturers need to consider when preparing lectures. In addition, both online and offline lectures need preparations by lecturers, which will undoubtedly take up more time. All of these are challenges for lecturers.

(3)Family environment support. If the flipping time is in school, whether the students can complete the flipping course part of the study unsupervised needs to be considered. However, if the flipped part is at home, not only the student's initiative must be considered, but also the degree of family support. Whether there is equipment or network support in the family, as it is understood that some students' families cannot support a good network or provide computers. In addition, can parents in the family understand their children and give them enough time and space to learn.

\subsubsection{Teaching Design}

Some investigations and empirical research on the course of Photoshop have been done in this research. "Graphics Processing (photoshopCC)" is a professional basic course for art design. Students usually study it in the freshman year or at the latest by the sophomore year. Courses started earlier in this college and are distributed across all majors of the college. In the teaching, according to the different majors, they are divided into "picture processing", "image processing photoshopCC" and "graphics and image processing". The arrangement of the course content is divided into two parts: online + offline.

The issues to be considered in teaching design are: 
(1)Analysis of students' learning conditions. Effective lesson preparation according to the characteristics of students is necessary. Some scholars have studied the different effects of video-based flipping teaching between different subjects. According to this research, it is mainly aimed at undergraduate art students as they are characterized by strong plasticity, strong learning initiative, and relatively strong self-learning ability based on videos.

(2)Course Design. In this empirical study, the teaching contents for the online and offline empirical study, the Photoshop course is divided into four major sections, namely the perceptual knowledge section, the project application section, the expanded creative section and the comprehensive practice section.

The perceptual knowledge section is mainly divided into basic knowledge of image processing, image drawing and editing, paths and graphics, adjustment of the color and tone of images, text and layers applications, and the use of channels and filters. This part introduces the application scope and new features of Photoshop, starting with the basic methods of drawing and editing images, and combining simple examples to gradually introduce Photoshop's layers, channels, masks, paths, actions, filters (including thirdparty Filters), text tools, shape tools and other advanced tools. Through this part of learning, students can master and apply the above advanced tools for graphic design and creative image processing.

This part is the main focus of the flipping. In this part of the course design, six chapters of videos were recorded online at the same time. Each chapter video is divided into several small knowledge points, such as the application of a small tool lasso, or the picture tone conversion. Such subdivided knowledge points amount to 5-15 per chapter. Students can watch and practice repeatedly at any time. In addition, offline synchronous courses use slightly more complicated cases, and each case involves about 5 knowledge points. Before the lecture, preview videos were provided for students. The length of each video is about 45 minutes. After attending the offline course, normal teaching will be carried out according to the offline lecture plan. Because the students have previewed the lecture, the learning progress of the offline course has been improved, and often there will be 30 minutes of extra time for lecturers to answer the students' questions. Q\&A sessions are mainly focused on the knowledge mastering in the classroom and the effect of pre-learning before lecture.
Some students will even look for some pictures they are interested in for consultation.

After online + offline, students' enthusiasm for independent learning has increased. The progress and proficiency of the students have improved significantly. As the number of offline and online cases increases, students are more interested in imitating the use of Photoshop, and create some graphics and image processing works after class.

The second module is project application. This part uses the mode of project application to learn the specific application of Photoshop in visual communication, product design, interior design, and fashion design. Deepen the mastery of the functions of Photoshop in the process of application, and integrate the aesthetic guidance to enhance the aesthetics in drawing excellent cases. This part highlights the basic principles of using Photoshop for creativity and a large number of case study, so that students will continue to learn the fun of Photoshop in the process of mastering these cases, so as to stimulate students' broader creative inspiration.

The third module is to expand creativity, a large number of creative cases were selected and combined with the advanced application functions of Photoshop, and further combined with external plug-ins such as Camera Raw, so that students can fully appreciate the powerful functions of Photoshop. Through case study, students can learn how to select Photoshop tools and commands.

The fourth module is comprehensive practice, combining real projects in real-time and using Photoshop to realize design creativity.

From the second part to the fourth part, the flipped content is reduced. Generally, after-school assignments are used to provide other course resources on the internet, so that students can complete and digest the case study by themselves, and then raise questions in the next lecture. Flipping was repeated in such manner, until the teaching of the course is completed.

\subsection{Research on the Effects of Flipped Classroom}

There are many issues to be considered in studying the effects of learning. The issues involved are listed below:

(1)Feedback from students. Studies have shown that students think that they take up too much time after class, which reduces their satisfaction with lecturers and courses.

(2)There have been some phenomena in the mastering of knowledge on Photoshop. Although the overall learning initiative has been improved, self- 
motivated students will study repeatedly to fully digest the knowledge points, and seek some more interesting cases to practice on their own, engaging in discussions and Q\&A with lecturers in class. Students lacking initiative will not even be able to fully grasp the flipped content. Of course, the overall learning effect is good, and the final standard of major assignments has been improved. The level of students' knowledge has been improved.

(1)In this study, the basic part of the first section of the Photoshop course was flipped a lot, while the latter part was flipped much less. Most students have good feedback on flipping, but the frequency and persistence of flipping must continue to be studied. The frequency and persistence of flipping are also important aspects that affect the effectiveness of the course. It is also necessary to consider that as this teaching was the first trial, so students felt a certain degree of novelty in it. If more classes are flipped, it may cause student becoming fatigue and result in poor results.

(2)The enthusiasm, initiative and creativity of students have been improved, and the online and offline synergy has also been improved. The intimacy between students is improved.

\section{Conclusion}

In the age of internet, flipped classroom teaching for Photoshop is applicable in terms of short-term teaching effects. Students' initiative, creativity and cooperation have all been improved. But there are still some problems to be solved and studied. For example, whether if the flipped classroom will have a continuous positive effect on students' learning in the long run, how to best segment the flipped courses, and whether the learning effect will be negatively affected when a large number of classes are flipped and students' time after class become more occupied. In addition, are the manpower and material costs too much after a large number of flipped teaching from an economic perspective etc.

\section{References}

[1] Jin LL. Research and Practice of Flipped Classroom Teaching Mode in the "Internet + " Era [J]. Internet of Things Technologies, 2016(5): 118-120.

[2] Stephanie GW. The Flipped Class: A Method to Address the Challenges of an Undergraduate Statistics Course[J]. Teaching of Psychology, 2015, 40(3): 193-199.

[3] Alison S B, Brian FD. "flipping" promote engagement?: A comparison of a traditional, online, and flipped class [J].Active Learning in Higher Education 2017, 18(1): 11-24

[4] Wai S. Tse, Lai Y. A. Choi and Wing S. Tang. Effects of videobased flipped class instruction on subject reading motivation[J]. British Journal of Educational Technology,2017: 1-14

[5] Gwo-Jen Hwang1, Chiu-Lin Lai, Siang-Yi Wang. Seamless flipped learning: a mobile technology-enhanced flipped classroom with effective learning strategies[J]. J. Comput. Educ. (2015) 2(4): 449-473

[6] E. A. van Vliet, J. C. Winnips, and N. Brouwer. Flipped-Class Pedagogy Enhances Student Metacognition and Collaborative-Learning Strategies in Higher Education But Effect Does Not Persist[J]. CBE-Life Sciences Education, Fall 2015, Vol. 14, 1-10

[7] Jamie L. Jensen, Tyler A. Kummer, and Patricia D. d. M. Godoy[J]. Improvements from a Flipped Classroom May Simply Be the Fruits of Active Learning, CBE-Life Sciences Education, Spring 2015: 14, 1-12 